\title{
Glycemic control and diabetes-related health care costs in type 2 diabetes; retrospective analysis based on clinical and administrative databases
}

This article was published in the following Dove Press journal:

ClinicoEconomics and Outcomes Research

13 May 2013

Number of times this article has been viewed

\section{Luca Degli Esposti' \\ Stefania Saragoni ${ }^{1}$ \\ Stefano Buda' \\ Alessandra Sturani ${ }^{2}$ \\ Ezio Degli Esposti'}

'CliCon Srl, Health, Economics and Outcomes Research, Ravenna, Italy; ${ }^{2} \mathrm{Nephrology}$ and Dialysis Unit, Santa Maria delle Croci Hospital, Ravenna, Italy
Correspondence: Luca Degli Esposti CliCon Srl, Health, Economics and Outcomes Research, Via Salara 36, 48100 Ravenna, Italy

Email luca.degliesposti@clicon.it
Background: Diabetes is one of the most prevalent chronic diseases, and its prevalence is predicted to increase in the next two decades. Diabetes imposes a staggering financial burden on the health care system, so information about the costs and experiences of collecting and reporting quality measures of data is vital for practices deciding whether to adopt quality improvements or monitor existing initiatives. The aim of this study was to quantify the association between health care costs and level of glycemic control in patients with type 2 diabetes using clinical and administrative databases.

Methods: A retrospective analysis using a large administrative database and a clinical registry containing laboratory results was performed. Patients were subdivided according to their glycated hemoglobin level. Multivariate analyses were used to control for differences in potential confounding factors, including age, gender, Charlson comorbidity index, presence of dyslipidemia, hypertension, or cardiovascular disease, and degree of adherence with antidiabetic drugs among the study groups.

Results: Of the total population of 700,000 subjects, 31,022 were identified as being diabetic ( $4.4 \%$ of the entire population). Of these, 21,586 met the study inclusion criteria. In total, $31.5 \%$ of patients had very poor glycemic control and $25.7 \%$ had excellent control. Over 2 years, the mean diabetes-related cost per person was: $€ 1291.56$ in patients with excellent control; $€ 1545.99$ in those with good control; $€ 1584.07$ in those with fair control; $€ 1839.42$ in those with poor control; and $€ 1894.80$ in those with very poor control. After adjustment, compared with the group having excellent control, the estimated excess cost per person associated with the groups with good control, fair control, poor control, and very poor control was $€ 219.28$, $€ 264.65$, €513.18, and $€ 564.79$, respectively.

Conclusion: Many patients showed suboptimal glycemic control. Lower levels of glycated hemoglobin were associated with lower diabetes-related health care costs. Integration of administrative databases and a laboratory database appears to be suitable for showing that appropriate management of diabetes can help to achieve better resource allocation.

Keywords: diabetes mellitus, glycemic control, $\mathrm{HbA}_{1 \mathrm{c}}$, health expenditure

\section{Introduction}

Diabetes is one of the most prevalent chronic diseases. The estimated prevalence of diabetes in the world population was $6.6 \%$ in 2010 , and this number is projected to increase to $7.8 \%$ by $2030 .{ }^{1}$ The condition commonly progresses to include microvascular and macrovascular complications. ${ }^{2,3}$ Development of diabetes-related complications is related to glycemic control. ${ }^{4}$ Diet and pharmacological treatment play a central role in the management of diabetes. However, according to the World Health Organization, only $50 \%$ of diabetic patients in developed countries comply with drug treatment. ${ }^{5,6}$ 
In addition, the National Health and Nutrition Examination Survey reported that only $37 \%$ of patients with diabetes have adequate disease control. ${ }^{7}$ In addition to its adverse effects on health and quality of life, diabetes also imposes a staggering financial burden on the health care system. The total cost of diabetes care is 2.3 times the cost of care for nondiabetic patients. ${ }^{8}$ In Italy, direct costs for people with diabetes amount to about 9 billion Euros per year, representing nearly $9 \%$ of the national health expenditure. ${ }^{9}$ Oglesby et al found that diabetes-related costs were $16 \%$ and $20 \%$ lower for patients with good control (glycated hemoglobin $\left[\mathrm{HbA}_{1 \mathrm{c}}\right] \leq 7 \%$ ) compared with those having fair control $\left(\mathrm{HbA}_{1 \mathrm{c}}>7 \%-9 \%\right)$ and poor control $\left(\mathrm{HbA}_{1 \mathrm{c}}>9 \%\right) .{ }^{10}$ Menzin et al reported that patients with a mean $\mathrm{HbA}_{1 \mathrm{c}} \geq 10 \%$ had higher diabetes-related hospital costs than those with a mean $\mathrm{HbA}_{1 \mathrm{c}}<7 \% .{ }^{11}$ Other data suggest that diabetes-related complications and consequent costs may be increased in patients with therapy targeted to very tight glycemic control. ${ }^{12}$

Estimates of the direct medical costs attributed to diabetes are essential to be able to assess the financial burden of the disease and plan for future health care needs. In addition, because type 2 diabetes is potentially preventable, ${ }^{13}$ estimates of medical expenditure are needed to assess the full economic effect of programs aimed at prevention of the disease. The data used to determine these policies are based either on disease registries clinical information or on administrative data. The former often involve population samples and are time-consuming and expensive to collect, whereas the latter have been used successfully as a source of information for diabetes monitoring. ${ }^{14,15}$

The aim of this study was to quantify the relationship between health care costs attributable to diabetes and level of glycemic control by cross-linkage of various large clinical and administrative databases in order to increase our understanding of the management of diabetes and be able to make informed policy decisions.

\section{Materials and methods Data source}

The study was based on administrative databases maintained by two local health units in Italy; Arezzo in Tuscany and Ravenna in Emilia-Romagna, representing a population of about 700,000 subjects. Using the Territorial Pharmacy Database, local health units routinely measure the volume of expenditure generated by dispensing of drugs to enrollees. The data available in each prescription claim include the patient's national health number, the prescribing physician's number, the anatomical-therapeutic-chemical (ATC) code of the drug dispensed, the number of packs dispensed, the number of units per pack, the dose, the unit cost per pack, and the prescription date. Using the anonymous alphanumeric code allocated to each citizen by the local health unit as a unique identifier to guarantee patient privacy, this database is linked with the Hospital Direct Drugs Distribution Registry, which contains the same data as the Territorial Pharmacy Database: the Beneficiaries' Database, listing patient demographic characteristics, ie, date of birth, gender, place of residence, physician license number, start and end of registration dates and the date of death; the Hospital Discharge Database, which includes all hospitalization data, with the principal and secondary discharge diagnosis codes classified according to the International Classification of Diseases, Ninth Revision (ICD9CM), and the diagnosisrelated group code; the Outpatient Service Registry, which includes all laboratory investigations, instrumental tests, and specialist checkups requests, and the dates on which these were performed; the Clinical Laboratory File, which records the test results of all laboratory tests performed. Universal health care coverage in Italy means that the information contained in these databases is complete and comprehensive, and has been used in previous epidemiological studies. ${ }^{16}$ The Italian Ministry of Health reports that these archives are $100 \%$ complete and $95 \%$ accurate. ${ }^{17}$ No identifiers related to patients were provided to the researchers. The ethics committees for the local health units approved the study.

\section{Cohort definition}

This was a retrospective cohort study, which included subjects identified as diabetic if, between January 1, 2009 and December 31, 2009, they had at least two prescriptions of antidiabetic drugs (ATC code A10), and/or at least one fasting glucose determination over $126 \mathrm{mg} / \mathrm{dL}$, and/or at least one hospitalization with a discharge diagnosis of diabetes (ICD9CM code 250), and/or at least one outpatient service with an exemption for diabetes. The date of the first prescription of antidiabetic medication, date of glucose determination, hospital discharge, and/or outpatient service was defined as the index date. The clinical characteristics of the patients enrolled in this study were investigated for the oneyear period before the index date. A two-year study period, starting from the index date, was evaluated for each patient. Patients were excluded if they were younger than 45 years, if they had only one determination of $\mathrm{HbA}_{1 \mathrm{c}}$ in the first or the second year of the study, if they had moved to another local health unit, or if they had died during the study period. 
Subjects enrolled were defined as: dyslipidemic based on the presence of at least two prescriptions of lipid-lowering drugs (ATC code C10) and/or at least one hospitalization with a primary or secondary diagnosis of metabolic syndrome (ICD9CM code 277.7) or disorder of lipid metabolism (ICD9CM code 272); as hypertensive based on the presence of at least two prescriptions of antihypertensive drugs (ATC code $\mathrm{C} 02, \mathrm{C} 03, \mathrm{C} 07, \mathrm{C} 08, \mathrm{C} 09)$ and/or a hospitalization with a primary or secondary diagnosis of hypertensive disease (ICD9CM code 401-405); as affected by a previous major cardiovascular event based on the presence of at least one hospitalization with a primary or secondary diagnosis of ischemic heart disease (ICD9CM code 410-414), heart failure (ICD9CM code 428), cerebrovascular disease (ICD9CM code 430-438), or arterial disease (ICD9CM code 440-442); as affected by a cardiovascular disease if they had a previous hospitalization for a cardiovascular event and/or had prescriptions for drugs acting on the renin-angiotensin system (ATC code C09A, C09B), antiplatelet drugs (ATC code B01 AC06), beta-blockers (ATC code C07), and/or antiplatelet drugs. The Charlson comorbidity index was also calculated for each patient by summing the assigned weights for all comorbid conditions evaluated in the one-year period before the index date. ${ }^{18}$ In addition, for the purposes of analysis, all $\mathrm{HbA}_{1 \mathrm{c}}$ measurements available during the follow-up period were identified. $\mathrm{HbA}_{1 \mathrm{c}}$ is a widely used marker of glycemic control that reflects the average glycemic level during the past 2-3 months. As in previous studies, the target $\mathrm{HbA}_{1 \mathrm{c}}$ was defined as $\leq 7 \% .{ }^{19}$ Enrolled patients were subdivided into five cohorts according to target $\mathrm{HbA}_{1 \mathrm{c}}$ values achieved: excellent ( $\geq 80 \%)$, good $(60 \%-79 \%)$, fair $(40 \%-59 \%)$, poor $(20 \%-39 \%)$, and very poor $(<20 \%)$. We also grouped patients without any determination of $\mathrm{HbA}_{1 \mathrm{c}}$.

\section{Adherence with antidiabetic medication}

Adherence was determined using the medication possession ratio (MPR). The MPR reflects the proportion of days during which the enrollee possesses a supply of medication.

\section{Sum of days' supply for all but the \\ MPR $=\frac{\text { last filling of antidiabetic medication }}{\text { Total number of days between first and last refill }}$}

For enrollees on multiple antidiabetic medications, the MPR reported was calculated as the mean of the MPR calculated for each drug. We excluded the number of days spent by the patients in an institutionalized care setting, such as hospital, from the MPR calculation. Because the Territorial
Pharmacy Database does not include data for drug dose, the mean daily dose of the prescribed drugs was defined according to the recommended dose reported in "L'Informatore Farmaceutico" for 2010. ${ }^{20}$ Patients were defined as adherent with antidiabetic medication if their MPR was $\geq 80 \%$.

\section{Cost of illness}

Cost of illness was measured using two different methods, ie, cohorts of people based on the percentage of $\mathrm{HbA}_{1 \mathrm{c}}$ levels $\leq 7 \%$, as previously described, or the first and last $\mathrm{HbA}_{1 \mathrm{c}}$ measurement during the study period. Disease-related health care costs evaluated in the study period included: costs of antidiabetic medication dispensed by the Territorial and Hospital Pharmacy; costs due to hospitalizations for fatal and nonfatal hypertensive disease (ICD9CM code 401-405); ischemic heart disease (ICD9CM code 410-414), heart failure (ICD9CM code 428), cerebrovascular disease (ICD9CM code 430-438), arterial disease (ICD9CM code 440-442), and diabetes (ICD9CM code 250); costs of laboratory/instrumental tests for $\mathrm{HbA}_{1 \mathrm{c}}$, glycemia, complete blood count, lipid panel, and albumin to creatinine ratio; and costs for specialist visits and eye examinations. Drug costs were evaluated using the National Health Service purchase price. Hospitalization costs were determined using the diagnosisrelated group tariff. The cost of instrumental and laboratory tests was defined according to the tariffs applied by the Emilia-Romagna and Tuscany regions. The currency reference used was the Euro $(€)$.

\section{Statistical analysis}

Quantitative variables are presented as the mean \pm standard deviation. One-way analysis of variance was used to compare the means for the quantitative variables. Associations between categoric variables were tested using the Pearson $\chi^{2}$ test. A generalized linear model with an identity link function and a gamma distribution was used to estimate the association between health care costs and level of glycemic control. ${ }^{21} \mathrm{To}$ control for confounding, we included in the model factors including age, gender, Charlson comorbidity index, coexisting illnesses (such as hypertension, dyslipidemia, and cardiovascular disease), and adherence level. Age was categorized as $\leq 65$ or $>65$ years; the Charlson score was grouped into three categories based on distribution of scores, ie, $\leq 1,2-3$, $\geq 4$; and adherence level was categorized based on the MPR value and grouped into three categories, ie, poor adherence (MPR $<40 \%$ ), fair adherence (MPR $40 \%$ to $<80 \%$ ), or good adherence (MPR $\geq 80 \%$ ). Two-tailed $P$-values $<0.05$ were considered to be statistically significant, and all statistical 


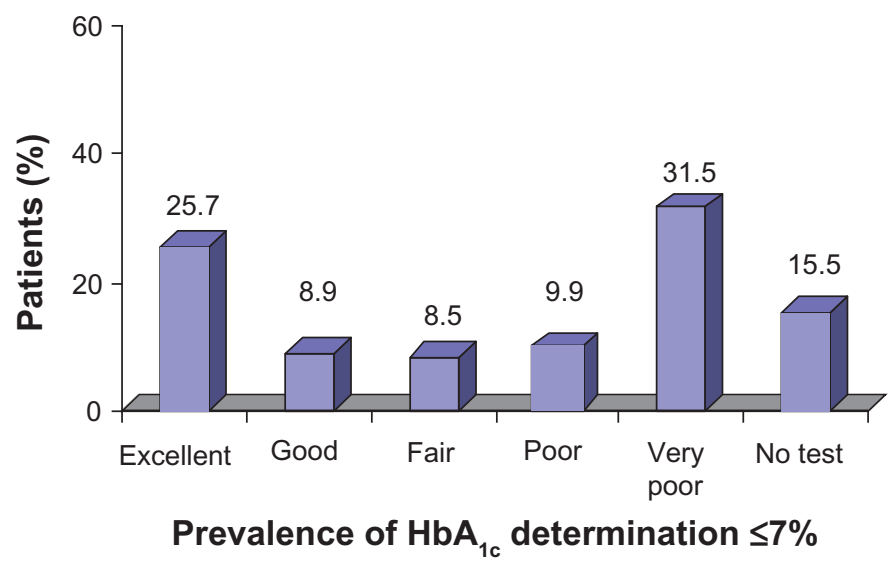

Figure I Prevalence of diabetic patients with different levels of glycemic control.

analyses were conducted using Stata software version 12.1 (Stata Corporation, College Station, TX, USA).

\section{Results}

Of the total study population of 700,000 subjects, 31,022 ( $4.4 \%$ of the entire population) were identified as diabetic. Of these, 9436 were excluded (1481 for being younger than 45 years; 5980 for having only one determination of $\mathrm{HbA}_{1 \mathrm{c}}$ in the first or second year of the study; and 1975 because they died or moved to another local health unit). We identified six cohorts of patients using $\mathrm{HbA}_{1 \mathrm{c}}$ levels (Figure 1). In total, 6807 patients $(31.5 \%)$ had very poor $\mathrm{HbA}_{1 \mathrm{c}}$ control, 5540 (25.7\%) had excellent control, and 3337 (15.5\%) did not have any determination of $\mathrm{HbA}_{1 \mathrm{c}}$ during the 2 years of the study. Patient characteristics are reported in Table 1. Patients without $\mathrm{HbA}_{1 \mathrm{c}}$ determinations were more frequently older than those with $\mathrm{HbA}_{1 \mathrm{c}}$ determinations, and had less concomitant illness and cardiovascular disease.

Worst is the glycemic control level, higher is the median value as well as the number of $\mathrm{HbA}_{1 \mathrm{c}}$ tests performed during the study period (Table 2). Table 3 and Figure 2 show glycemic control expressed as $\mathrm{HbA}_{1 \mathrm{c}} \leq 7 \%$ in relation to the number of antidiabetic drugs prescribed for each patient. There were 2046 patients $(9.5 \%$ of the entire study population) with no prescriptions for antidiabetic medication, 7633 patients (35.4\%) with prescriptions for one drug, 6204 (28.7\%) with prescriptions for two drugs, and $5703(26.4 \%)$ with prescriptions for three or more drugs. The majority (53.6\%) of untreated patients did not have any $\mathrm{HbA}_{1 \mathrm{c}}$ measurements recorded. In contrast, the number of treated patients without $\mathrm{HbA}_{1 \mathrm{c}}$ determinations was very low, ranging from $18.7 \%$ to $4.2 \%$. Moreover, in the group of patients with excellent control, 39.6\% maintained their target $\mathrm{HbA}_{1 \mathrm{c}}$ level successfully using a single drug whereas subjects with very poor control failed to maintain their target $\mathrm{HbA}_{1 \mathrm{c}}$ level despite intensification of treatment $(56.1 \%$ were prescribed more than two drugs).

The rate of adherence with antidiabetic medication (Table 4) was significantly different in the six cohorts of

Table I Characteristics of enrolled patients

\begin{tabular}{|c|c|c|c|c|c|c|c|c|}
\hline & \multicolumn{7}{|c|}{ Glycemic control level } & \multirow[t]{2}{*}{$P$-value } \\
\hline & Excellent & Good & Fair & Poor & Very poor & No test & Total & \\
\hline $\mathrm{n}$ & 5540 & 1924 & 1844 & 2134 & 6807 & 3337 & 21,586 & \\
\hline Mean age (years) & 69.3 & 69.2 & 69.2 & 69.5 & 69.1 & 71.5 & 69.6 & $<0.001$ \\
\hline Male gender $(\%)$ & 55.2 & 51.8 & 51.5 & 53.7 & 47.7 & 54.7 & 52.1 & $<0.001$ \\
\hline Charlson comorbidity index (\%) & & & & & & & & $<0.001$ \\
\hline$\leq 1$ & 71.3 & 71.0 & 71.4 & 68.9 & 65.7 & 62.3 & 67.9 & \\
\hline $2-3$ & 24.9 & 25.7 & 25.0 & 26.8 & 30.5 & 32.9 & 28.2 & \\
\hline$\geq 4$ & 3.8 & 3.2 & 3.6 & 4.3 & 3.9 & 4.8 & 3.9 & \\
\hline Dyslipidemia (\%) & 49.4 & 54.2 & 53.0 & 54.5 & 56.4 & 29.2 & 49.7 & $<0.001$ \\
\hline Hypertension (\%) & 77.0 & 76.7 & 76.5 & 77.4 & 75.2 & 72.8 & 75.8 & $<0.001$ \\
\hline Previous CV hospitalization (\%) & 6.2 & 5.8 & 7.5 & 6.6 & 6.6 & 7.4 & 6.6 & 0.105 \\
\hline CV disease (\%) & 31.9 & 31.1 & 34.3 & 32.8 & 35.4 & 30.3 & 33.0 & $<0.001$ \\
\hline
\end{tabular}

Abbreviation: $\mathrm{CV}$, cardiovascular. 
Table 2 Number of determinations and median values for $\mathrm{HbA}_{\mathrm{lc}}$

\begin{tabular}{|c|c|c|c|c|c|c|}
\hline & \multicolumn{5}{|c|}{ Glycemic control level } & \multirow[t]{2}{*}{$P$-value } \\
\hline & Excellent & Good & Fair & Poor & Very poor & \\
\hline $\begin{array}{l}\mathrm{HbA}_{\mathrm{Ic}} \text { median value \% } \\
(\mathrm{IQR})\end{array}$ & $6.4(0.5)$ & $6.9(0.3)$ & $7.1(0.3)$ & $7.4(0.5)$ & $8.2(1.1)$ & $<0.001$ \\
\hline $\begin{array}{l}\mathrm{HbA}_{\mathrm{Ic}} \text { determination, } \\
\text { mean number }(\mathrm{SD})\end{array}$ & $4.5(2.2)$ & $5.0(2.3)$ & $5.1(2.5)$ & $5.3(2.6)$ & $5.5(2.6)$ & $<0.001$ \\
\hline
\end{tabular}

Abbreviations: $\mathrm{HbA}_{1 \mathrm{c}}$, glycated hemoglobin; IQR, interquartile range; $\mathrm{SD}$, standard deviation.

diabetic patients, being $6.7 \%-4.6 \%$ in $<40 \%$ and $64.7 \%$ $60.1 \%$ in $\geq 80 \%$.

Total health care costs were calculated to be $€ 30,433,264.79$ and the mean cost per patient was $€ 1557.49$. The mean cost calculated per patient according to the prevalence of $\mathrm{HbA}_{1 \mathrm{c}} \leq 7 \%$ (Table 5 ) showed a progressive and significant increase correlating with a progressive decrease in control of $\mathrm{HbA}_{1 \mathrm{c}}$, from $€ 1291.56$ in patients with excellent control to $€ 1894.80$ in patients with very poor control. Patients without any $\mathrm{HbA}_{1 \mathrm{c}}$ tests showed the lowest mean cost at $€ 859.90$. Older age, presence of hypertension, dyslipidemia, cardiovascular disease, and uncontrolled $\mathrm{HbA}_{1 \mathrm{c}}$ were factors that contributed significantly to increased health care costs in these patients (Table 6).

We also analyzed health care costs according to the first and last $\mathrm{HbA}_{1 \mathrm{c}}$ levels recorded during the study period (Table 7). The intervals between the first and last $\mathrm{HbA}_{1 \mathrm{c}}$ determinations were similar in all cohorts, and in the range of 17.1-18.4 months. The mean cost per patient increased progressively in patients with stable $\mathrm{HbA}_{1 \mathrm{c}}<7 \%, 7.1 \%-8 \%$, $8.1 \%-9 \%$, and $>9 \%$. There was an increment in mean health care costs in patients with worsening control of $\mathrm{HbA}_{1 \mathrm{c}}$. Analysis of the different components of health care costs (Table 8) showed that the progressive incremental cost was mainly because of antidiabetic drugs, hospitalizations for diabetes-related problems, and use of outpatient services.

Table 3 Number of antidiabetic drugs prescribed in the different cohorts of diabetic patients

\begin{tabular}{|c|c|c|c|c|c|c|c|c|}
\hline \multirow{3}{*}{$\begin{array}{l}\text { Glycemic } \\
\text { control } \\
\text { level }\end{array}$} & \multicolumn{8}{|c|}{ Antidiabetic drugs prescribed (n) } \\
\hline & \multicolumn{2}{|l|}{0} & \multicolumn{2}{|l|}{$\mathbf{I}$} & \multicolumn{2}{|l|}{2} & \multicolumn{2}{|l|}{$>2$} \\
\hline & $\mathbf{n}$ & $\%$ & $\mathbf{n}$ & $\%$ & $\mathbf{n}$ & $\%$ & $\mathbf{n}$ & $\%$ \\
\hline Excellent & 617 & 30.2 & 3023 & 39.6 & 1379 & 22.2 & 521 & 9.1 \\
\hline Good & 103 & 5.0 & 739 & 9.7 & 657 & 10.6 & 425 & 7.5 \\
\hline Fair & 70 & 3.4 & 619 & 8.1 & 599 & 9.7 & 556 & 9.7 \\
\hline Poor & 44 & 2.2 & 580 & 7.6 & 748 & 12.1 & 762 & 13.4 \\
\hline Very poor & 116 & 5.7 & 1244 & 16.3 & 2250 & 36.3 & 3197 & 56.1 \\
\hline No test & 1096 & 53.6 & 1428 & 18.7 & 571 & 9.2 & 242 & 4.2 \\
\hline Total & 2046 & 100.0 & 7633 & 100.0 & 6204 & 100.0 & 5703 & 100.0 \\
\hline
\end{tabular}

\section{Discussion}

Diabetes registries have been used for years to evaluate clinical care provided by health systems, ${ }^{22}$ and are usually created from administrative data, such as those for hospital discharge diagnoses and pharmaceutical claims. ${ }^{23,24}$ The availability of detailed clinical data, including real-time laboratory test results, has improved the ability to build more sophisticated and accurate diabetes registries that capture more precisely defined cohorts of individuals with diabetes. With regard to laboratory tests, we selected plasma glucose and $\mathrm{HbA}_{1 \mathrm{c}}$ levels to create the linkage with clinical and administrative databases. In addition to antidiabetic medication, we used three further criteria to identify diabetic patients, and documented a diabetes prevalence of $4.4 \%$, which makes our cohort comparable with the entire Italian population. ${ }^{25}$ Moreover, these criteria enabled identification of $9.5 \%$ of subjects who were not treated with antidiabetic medication. About half of these untreated subjects did not have any determination of $\mathrm{HbA}_{1 \mathrm{c}}$, while the majority of the remaining subjects had excellent $\mathrm{HbA}_{1 \mathrm{c}}$ control. This apparently conflicting profile could be because: firstly, the presence in this cohort of a high percentage of subjects defined as diabetic on the basis of a single determination of fasting plasma glucose $>126 \mathrm{mg} / \mathrm{dL}$, which might be considered the weakest of the criteria we used; secondly, the inability of this analysis to capture diet and exercise habits, which have been shown to have a positive impact on glycemic control. The importance of the criteria used for inclusion in such registries is not trivial. For example, in a sample of residents of Ontario, Canada, Harris et al showed that the prevalence of diabetes ranged from $5 \%$ to $12 \%$ depending on which combinations of laboratory, pharmacy, and diagnosis data were used. ${ }^{26}$ To determine the quality of control of diabetes in clinical practice, we subdivided our patients into five cohorts according to the percentage of $\mathrm{HbA}_{1 \mathrm{c}}$ levels $\leq 7 \%$ during the two-year study period. $\mathrm{HbA}_{1 \mathrm{c}}$ concentration is a good indicator of glycemic control during the previous 8-12 weeks and is used as the standard biomarker for the efficacy of glycemic 


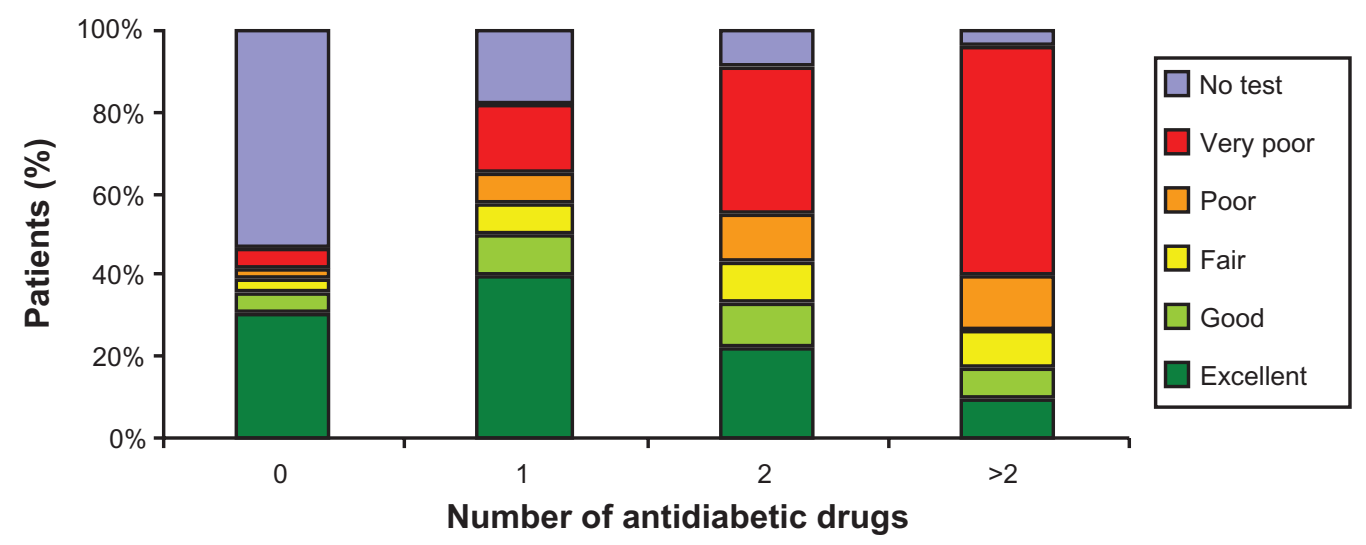

Figure 2 Prevalence of different levels of glycemic control in diabetic patients categorized according to number of antidiabetic drugs prescribed.

management because it correlates well with development of microvascular complications and also (albeit to a lesser extent) macrovascular complications, according to a large epidemiological study. ${ }^{27,28}$ The treatment guidelines for patients with type 2 diabetes that existed during the study period recommended a target $\mathrm{HbA}_{1 \mathrm{c}}$ level of $\leq 7 \%,{ }^{29}$ although the National Institute for Health and Clinical Excellence has more recently recommended a target $\mathrm{HbA}_{1 \mathrm{c}}$ level of $\leq 7.5 \%{ }^{30}$ Despite these recommendations, most patients still do not achieve their target $\mathrm{HbA}_{1 \mathrm{c}}$ level in general practice. ${ }^{7,31}$ Among our diabetic patients with $\mathrm{HbA}_{1 \mathrm{c}}$ determinations, only $25.7 \%$ had excellent control of diabetes (median $\mathrm{HbA}_{1 \mathrm{c}} 6.4 \%$ ) and $8.9 \%$ had good control $(6.9 \%)$, while $31.5 \%$ had very poor control $(8.2 \%)$. Of note is that more than $60 \%$ of patients in each of our study cohorts showed $\geq 80 \%$ adherence with antidiabetic medication, which is greater than the adherence figures reported by the World Health Organization, ${ }^{6}$ and indicates that the quality of glycemic control decreases with increasing numbers of antidiabetic prescriptions. Other authors have documented significant differences in the use of diabetic medication at different levels of $\mathrm{HbA}_{1 \mathrm{c}}$ control. ${ }^{10}$ In order to quantify the association between health care costs attributable to diabetes and quality of control of diabetes in clinical practice, we used two different calculation methods, ie, one based on the percentage of $\mathrm{HbA}_{1 \mathrm{c}}$ levels $\leq 7 \%$ and the other based on the first and the last determinations of $\mathrm{HbA}_{1 \mathrm{c}}$. Using the first method, we identified five cohorts. Patients with very poor $\mathrm{HbA}_{1 \mathrm{c}}$ control (less than $20 \%$ of $\mathrm{HbA}_{1 \mathrm{c}}$ determinations $\leq 7 \%$ ) showed a cost per year increment of $46.7 \%$ (€947.40) compared with those having excellent control (more than $80 \%$ of $\mathrm{HbA}_{1 \mathrm{c}}$ determinations $\leq 7 \%$ ) who had a cost per year of $€ 645.78$. Our findings using this method of analysis highlight the significant differences in cost associated with each of the five levels of glycemic control. Even patients considered to have fair glycemic control, ie, $\mathrm{HbA}_{1 \mathrm{c}} 7.1 \%-9 \%$, had significantly higher total and prescription costs attributable to diabetes than patients with excellent glycemic control.

Using the second method, we identified sixteen cohorts of patients. Those with a first-last $\mathrm{HbA}_{1 \mathrm{c}}$ determination $>9 \%$ compared with those with a first-last $\mathrm{HbA}_{1 \mathrm{c}}$ determination $\leq 7 \%$ showed an annual cost increment of $63.2 \%$ ( $€ 1042.37$ versus $€ 638.67$, respectively). In general, we found a significant cost increment when the $\mathrm{HbA}_{1 \mathrm{c}}$ increased during the follow-up period independent of the initial level, whereas decreasing $\mathrm{HbA}_{1 \mathrm{c}}$, although advantageous in the short-term, did not significantly change costs. Our findings also indicate that a modest (around 1\%) incremental worsening of $\mathrm{HbA}_{1 \mathrm{c}}$ resulted

Table 4 Adherence to antidiabetic medication in different cohorts of diabetic patients

\begin{tabular}{|c|c|c|c|c|c|c|c|c|c|c|c|c|c|c|}
\hline \multirow{3}{*}{$\begin{array}{l}\text { Adherence } \\
\text { to antidiabetic } \\
\text { drugs* }\end{array}$} & \multicolumn{14}{|c|}{ Glycemic control level } \\
\hline & \multicolumn{2}{|c|}{ Excellent } & \multicolumn{2}{|c|}{ Good } & \multicolumn{2}{|l|}{ Fair } & \multicolumn{2}{|l|}{ Poor } & \multicolumn{2}{|c|}{ Very poor } & \multicolumn{2}{|c|}{ No test } & \multicolumn{2}{|l|}{ Total } \\
\hline & $\mathbf{n}$ & $\%$ & $\mathbf{n}$ & $\%$ & $\mathbf{n}$ & $\%$ & $\mathbf{n}$ & $\%$ & $\mathbf{n}$ & $\%$ & $\mathbf{n}$ & $\%$ & $\mathbf{n}$ & $\%$ \\
\hline$<40 \%$ & 330 & 6.7 & 94 & 5.2 & 82 & 4.6 & 101 & 4.8 & 306 & 4.6 & 221 & 6.4 & 1134 & 5.8 \\
\hline $40 \%-79 \%$ & 1636 & 33.2 & 590 & 32.4 & 544 & 30.7 & 658 & 31.5 & 2142 & 32.0 & 802 & 31.3 & 6372 & 32.6 \\
\hline$\geq 80 \%$ & 2957 & 60.1 & 1137 & 62.4 & 1148 & 64.7 & $|33|$ & 63.7 & 4243 & 63.4 & 1218 & 62.3 & 12034 & 61.6 \\
\hline Total & 4923 & 100.0 & $|82|$ & 100.0 & 1774 & 100.0 & 2090 & 100.0 & 6691 & 100.0 & 2241 & 100.0 & 19540 & 100.0 \\
\hline
\end{tabular}

Note: $* p<0.001$. 
Table 5 Health care costs in different cohorts of diabetic patients

\begin{tabular}{|c|c|c|c|c|c|c|c|}
\hline & \multicolumn{7}{|c|}{ Glycemic control level } \\
\hline & Excellent & Good & Fair & Poor & Very poor & No test & Total \\
\hline Patients (n) & 4923 & $|82|$ & 1774 & 2090 & 6691 & 2241 & 19,540 \\
\hline Total $(€)$ & $6,358,342.03$ & $2,815,248.53$ & $2,810,142.19$ & $3,844,394.14$ & $12,678,098.98$ & $1,927,038.92$ & $30,433,264.79$ \\
\hline Mean $(€)$ & $\begin{array}{l}1291.56 \pm \\
3301.27\end{array}$ & $\begin{array}{l}1545.99 \pm \\
3535.66\end{array}$ & $\begin{array}{l}1584.07 \pm \\
3453.53\end{array}$ & $\begin{array}{l}1839.42 \pm \\
3743.26\end{array}$ & $\begin{array}{l}1894.80 \pm \\
3773.76\end{array}$ & $\begin{array}{l}859.90 \pm \\
2693.76\end{array}$ & $\begin{array}{l}1557.49 \pm \\
3509.89\end{array}$ \\
\hline
\end{tabular}

in greater health care costs and increased resource utilization in the two-year study period. However, modest incremental improvements in $\mathrm{HbA}_{1 \mathrm{c}}$ control may not be sufficient to reduce costs in a meaningful way. The amount of antidiabetic medication prescribed, number of outpatient attendances, and frequency of hospitalizations for diabetes-related reasons contributed to the increased costs. Other researchers have found that reduction of $\mathrm{HbA}_{1 \mathrm{c}}$ to $\leq 7 \%$ was associated with a $30 \%$ decrease in expenditure on long-term health care, and patients with $\mathrm{HbA}_{1 \mathrm{c}} \leq 8 \%$ had a lower likelihood of hospitalization. ${ }^{10,32,33}$ This mixed-methods assessment of the cost and issues surrounding quality of measurement of glycemic control and use in primary care practices yielded interesting results. The data we collected enabled estimation of costs per patient in a context more easily understood by payers and policymakers.

Table 6 Multivariate regression analysis

\begin{tabular}{|c|c|c|c|c|}
\hline \multirow[b]{2}{*}{ Constant } & \multirow{2}{*}{$\frac{\text { B }}{362.04}$} & \multicolumn{2}{|c|}{ (95\% Cl for $\mathrm{B})$} & \multirow{2}{*}{$\frac{P \text {-value }}{<0.001}$} \\
\hline & & 294.97 & 470.07 & \\
\hline Age $>65$ years & 280.33 & 277.51 & 446.57 & $<0.001$ \\
\hline Male gender & 296.03 & 204.26 & 356.39 & $<0.001$ \\
\hline \multicolumn{5}{|l|}{ Charlson comorbidity index ${ }^{\wedge}$} \\
\hline $2-3$ & -21.01 & -87.87 & 45.85 & 0.538 \\
\hline$>3$ & 267.93 & $-|3.9|$ & 549.78 & 0.062 \\
\hline Hypertension* & 281.65 & 191.51 & 371.79 & $<0.001$ \\
\hline Dyslipidemia* & 346.85 & 259.19 & 434.50 & $<0.001$ \\
\hline Cardiovascular disease* & 2102.80 & 1631.75 & 2573.85 & $<0.001$ \\
\hline \multicolumn{5}{|l|}{ Adherence level** } \\
\hline$<40 \%$ & 63.11 & $-|4.2|$ & 140.43 & 0.110 \\
\hline $40 \%-79 \%$ & -128.67 & -211.05 & -46.29 & 0.002 \\
\hline \multicolumn{5}{|l|}{ Glycemic control level*** } \\
\hline Good & 219.28 & 75.25 & 363.30 & 0.003 \\
\hline Fair & 264.65 & 117.03 & 412.27 & $<0.001$ \\
\hline Poor & 513.18 & 345.13 & 681.23 & $<0.001$ \\
\hline Very poor & 564.79 & 456.35 & 673.23 & $<0.001$ \\
\hline No test & -151.24 & -235.09 & -67.38 & $<0.001$ \\
\hline
\end{tabular}

Notes: ^Reference, Charlson index $\leq \mathrm{I}$; *reference, no treatment or no diagnosis of cardiovascular disease; **reference, adherence level $\geq 80 \%$; ***reference, excellent control. Constant is the expected health care cost when all the covariates have been set to their reference values.

Abbreviations: $\mathrm{B}$, regression coefficient; $\mathrm{Cl}$, confidence interval.
The findings of the present study must be interpreted in light of some limitations. First, the analyses were performed using the databases of two local health units located in the north-center of Italy. Although these databases were deemed to cover the area of the local health units adequately, the results may not be generalizable to other populations. Second, the analysis only included subjects receiving antidiabetic medication, so it is unknown if all of our study subjects had a formal diagnosis of type 2 diabetes. However, we excluded subjects younger than 45 years of age to minimize the risk of inclusion of subjects with type 1 diabetes, which is common practice in retrospective analyses of databases. ${ }^{34,35}$ Menzin et al found a higher prevalence of patients with type 1 diabetes in the younger age groups. ${ }^{11}$ Third, we did not examine place of residence, which could confound the association between glycemic control and diabetes-related health care costs. Fourth, we were unable to define time since initial diagnosis, a factor that may influence response to antidiabetic medication, level of glycemic control, and costs. Fifth, we only considered subjects receiving oral antidiabetic drugs or a combination of oral agents and insulin. Future work using alternative approaches, eg, based on type of medication that subjects require, may be of interest. Sixth, we did not consider costs related to other therapies (eg, lipid-lowering or antihypertensive medication) or hospitalizations for any other reason, which are both factors that may contribute to underestimation of the cost per patient. Finally, the two-year study period was too short to evaluate cardiovascular morbidity and total mortality. In conclusion, our study shows that cross-linkage between various clinical and administrative databases is critical for successfully implementing systems of care that are valuebased. To be adopted and embraced fully, systems must be applicable to patient care across payment sources and must have adequate patient volumes in order to identify patient characteristics influencing costs and be able to estimate the expected costs of quality improvement or deterioration. Our results indicate that glycemic control (ie, $\mathrm{HbA}_{1 \mathrm{c}}$ level) is a useful surrogate not only for diabetes-related complications but also for the associated health care costs. 
Table 7 Mean cost per patient in different cohorts of diabetic patients determined according to the levels of first and last $\mathrm{HbA}_{\mathrm{Ic}}$ determination performed during the study

\begin{tabular}{|c|c|c|c|c|}
\hline \multirow{2}{*}{$\begin{array}{l}\text { Last HbA } \mathrm{Al}_{\mathrm{Ic}} \\
\text { level }\end{array}$} & \multicolumn{4}{|c|}{ Baseline $\mathrm{HbA}_{\mathrm{Ic}}$ level } \\
\hline & $\leq 7.0$ & $\begin{array}{l}>7.0 \\
\text { to } \leq \mathbf{8 . 0}\end{array}$ & $\begin{array}{l}>8.0 \\
\text { to } \leq 9.0\end{array}$ & $>9$ \\
\hline$\leq 7$ & $1277.35 \pm 3226.27$ & $1675.57 \pm 4046.27$ & $2037.18 \pm 4625.92$ & $1896.18 \pm 3684.02$ \\
\hline$>7.0$ to $\leq 8.0$ & $|5| 2.66 \pm 3678.53$ & $1487.79 \pm 3035.17$ & $1839.75 \pm 3555.66$ & $2281.92 \pm 4725.64$ \\
\hline$>8.0$ to $\leq 9.0$ & $1776.12 \pm 4355.22$ & $2032.54 \pm 4543.08$ & $|844.87 \pm 3| 46.6 \mid$ & $2136.09 \pm 3938.02$ \\
\hline$>9.0$ & $2176.66 \pm 4194.85$ & $2086.86 \pm 33|2.5|$ & $2322.20 \pm 3955.73$ & $2084.75 \pm 3579.18$ \\
\hline
\end{tabular}

Abbreviation: $\mathrm{HbA}_{1 \mathrm{c}}$, glycated hemoglobin.

Table 8 Distribution of health care costs

\begin{tabular}{|c|c|c|c|c|c|}
\hline & \multicolumn{5}{|c|}{ Stable $\mathrm{HbA}_{\mathrm{Ic}}$ levels } \\
\hline & $\leq 7.0$ & $>7.0$ to $\leq 8.0$ & $>8.0$ to $\leq 9.0$ & $>9$ & Total \\
\hline$n$ & 5221 & 2492 & 849 & 699 & 9261 \\
\hline \multicolumn{6}{|c|}{ Antidiabetic drugs } \\
\hline Total $(€)$ & I,257,794.82 & I,09I,827.00 & $630,897.08$ & $582,377.94$ & $3,562,896.84$ \\
\hline Mean $(€)$ & $240.91 \pm 319.79$ & $438.13 \pm 453.18$ & $743.11 \pm 687.62$ & $833.16 \pm 818.60$ & $384.72 \pm 496.07$ \\
\hline \multicolumn{6}{|c|}{ CV hospitalizations } \\
\hline Total $(€)$ & $3,640,317.44$ & I,695,460.00 & $582,458.05$ & $510,201.86$ & $6,428,437.42$ \\
\hline Mean $(€)$ & $697.25 \pm 2873.34$ & $680.36 \pm 2614.14$ & $686.05 \pm 2796.09$ & $729.90 \pm 3068.32$ & $694.14 \pm 2813.92$ \\
\hline \multicolumn{6}{|c|}{ Hospitalizations for diabetes } \\
\hline Total $(€)$ & $309,145.94$ & $240,148.00$ & $521,60.71$ & $|46,2| 4.79$ & $747,669.48$ \\
\hline Mean $(€)$ & $59.21 \pm 665.68$ & $96.37 \pm 1211.42$ & $61.44 \pm 679.75$ & $209.18 \pm 1107.53$ & $80.73 \pm 883.71$ \\
\hline \multicolumn{6}{|c|}{ Outpatient services } \\
\hline Total $(€)$ & $1,474,236.30$ & $763,007.50$ & $293,648.87$ & $230,290.28$ & $2,761,182.99$ \\
\hline Mean $(€)$ & $282.37 \pm 234.73$ & $306.18 \pm 201.29$ & $345.88 \pm 212.00$ & $329.46 \pm 233.71$ & $298.15 \pm 225.02$ \\
\hline \multicolumn{6}{|l|}{ Total } \\
\hline Total $(€)$ & $6,681,494.50$ & $3,790,443.00$ & $I, 559,164.7 \mid$ & $1,469,084.87$ & $|3,938,048.5|$ \\
\hline Mean $(€)$ & $1279.73 \pm 3140.15$ & $|52| .04 \pm 3073.86$ & $|836.47 \pm 3| 33.04$ & $2101.70 \pm 3589.82$ & $1505.03 \pm 3356.97$ \\
\hline
\end{tabular}

Abbreviations: $\mathrm{HbA}_{\mathrm{lc}}$, glycated hemoglobin; $\mathrm{CV}$, cardiovascular.

\section{Disclosure}

The authors declare no conflicts of interest in this work.

\section{References}

1. International Diabetes Federation. Diabetes Atlas, 4th ed. Brussels, Belgium: International Diabetes Federation; 2009. Available from: http:// www.diabetesatlas.org/content/diabetes. Accessed March 29, 2013.

2. Sobel BE, Schneider DJ. Cardiovascular complications in diabetes mellitus. Curr Opin Pharmacol. 2005;5:143-148.

3. Grundy SM, Benjamin IJ, Burke GL, et al. Diabetes and cardiovascular disease: a statement for healthcare professionals from the American Heart Association. Circulation. 1999;100:1134-1146.

4. Stolar M. Glycemic control and complications in type 2 diabetes mellitus. Am J Med. 2010;123 Suppl:S3-S11.

5. Nichols-English G, Poirier S. Optimizing adherence to pharmaceutical care plans. J Am Pharm Assoc. 2000;40:475-485.

6. World Health Organization. Adherence to long-term therapies: evidence for action. Geneva, Switzerland: World Health Organization. Available from: http://whqlibdoc.who.int/publications/2003/9241545992.pdf. Accessed March 31, 2013.

7. Saydah S, Fradkin J, Cowie CC. Poor control of risk factors for vascular disease among adults with previously diagnosed diabetes. JAMA. 2004;291:335-342.
8. National Diabetes Information Clearinghouse. National diabetes statistics, 2011. Available from: http://diabetes.niddk.nih.gov/dm/pubs/ statistics/. Accessed March 29, 2013.

9. Lauro R, Nicolucci A. Public Health and Health Policy. An informed health policy on chronic diseases. Scientific Editor: Consorzio Mario Negri Sud; 2011.

10. Oglesby AK, Secnik K, Barron J, Al-Zakwani I, Lage MJ. The association between diabetes-related medical costs and glycemic control: a retrospective analysis. Cost Eff Resour Alloc. 2006;4:1.

11. Menzin J, Korn J, Cohen J, Lobo F. Relationship between glycemic control and diabetes-related hospital costs in patients with type 1 or type 2 diabetes mellitus. J Manag Care Pharm. 2010;16:264-275.

12. Kelly TN, Bazzano LA, Fonseca VA, Thethi TK, Reynolds K, He J. Systematic review: glucose control and cardiovascular disease in type 2 diabetes. Ann Intern Med. 2009;151:394-403.

13. Tuomilehto J, Lindstrom J, Eriksson JG, et al. Prevention of type 2 diabetes mellitus by changes in lifestyle among subjects with impaired glucose tolerance. N Engl J Med. 2001;344:1343-1350.

14. Hux JE, Ivis F, Flintoft V, Bica A. Diabetes in Ontario: determination of prevalence and incidence using a validated administrative data algorithm. Diabetes Care. 2002;25:512-516.

15. Solberg LI, Engebretson KI, Sperl-Hillen JM, Hroscikoski MC, O'Connor PJ. Are claims data accurate enough to identify patients for performance measures or quality improvement? The case of diabetes, heart disease, and depression. Am J Med Qual. 2006;21:238-245. 
16. Di Bari M, Balzi D, Roberts AT, et al. Prognostic stratification of older persons based on simple administrative data: development and validation of the "Silver Code", to be used in emergency department triage. J Gerontol A Biol Sci Med. 2010;65:159-164.

17. Ministero del Lavoro, della Salute e delle Politiche Sociali. [Ministry of Labour, Health and Social Policies. Annual report on the hospitalization activity]. 2005. Available from: http://www.ministerosalute.it/ programmazione/sdo/sezDocumenti.jsp?id=148\&label=osp. Accessed April 24, 2009. Italian.

18. Charlson ME, Pompei P, Ales KL, McKenzie CR. A new method of classifying prognostic comorbidity in longitudinal studies: development and validation. J Chronic Dis. 1987;40:373-383.

19. Lawrence DB, Ragucci KR, Long LB, Parris BS, Helfer LA. Relationship of oral antihyperglycemic (sulfonylurea or metformin) medication adherence and hemoglobin A1c goal attainment for HMO patients enrolled in a diabetes disease management program. J Manag Care Pharm. 2006;12:466-471.

20. Informatore farmaceutico - Medicinali [Pharmaceutical Informer Drugs]. 2012; Elsevier, Italy. Italian.

21. Barber J, Thompson S. Multiple regression of cost data: use of generalised linear models. J Health Serv Res Policy. 2004;9:197-204.

22. Khan L, Mincemoyer S, Gabbay RA. Diabetes registries: where we are and where are we headed? Diabetes Technol Ther. 2009;11: 255-262.

23. Brown JB, Nichols GA, Glauber HS. Case control study of 10 years of comprehensive diabetes care. West J Med. 2000;172:85-90.

24. Selby JV, Ray GT, Zhang D, Colby CJ. Excess costs of medical care for patients with diabetes in a managed care population. Diabetes Care. 1997;20:1396-1402.

25. ISTAT. [Health conditions and use of health services] 2008. Available from: http://www.ministerosalute.it/imgs/C_17_pubblicazioni_609_ allegato.pdf. Italian.

26. Harris SB, Glazier RH, Tompkins JW, et al. Investigating concordance in diabetes diagnosis between primary care charts (electronic medical records) and health administrative data: retrospective cohort study. $B M C$ Health Serv Res. 2010;10:347.
27. Stratton IM, Adler AI, Neil HA, et al. Association of glycaemia with macrovascular and microvascular complications of type 2 diabetes (UKPDS 35): prospective observational study. BMJ. 2000;321: 405-412.

28. The Diabetes Control and Complications Trial Research Group. The relationship of glycemic exposure $\left(\mathrm{HbA}_{1 \mathrm{c}}\right)$ to the risk of development and progression of retinopathy in the diabetes control and complications trial. Diabetes. 1995;44:968-983.

29. [No authors listed]. Standards of medical care in diabetes -2009. Diabetes Care. 2009;32 Suppl 1:S13-S61.

30. National Collaborating Centre for Chronic Conditions. Type 2 Diabetes: National Clinical Guideline for Management in Primary and Secondary Care (Update). London, UK: Royal College of Physicians; 2008.

31. Alvarez Guisasola F, Mavros P, Nocea G, Alemao E, Alexander CM, Yin D. Glycaemic control among patients with type 2 diabetes mellitus in seven European countries: findings from the Real-Life Effectiveness and Care Patterns of Diabetes Management (RECAP-DM) study. Diabetes Obes Metab. 2008;10 Suppl 1:8-15.

32. Menzin J, Langley-Hawthorne C, Friedman M, Boulanger L, Cavanaugh R. Potential short-term economic benefits of improved glycemic control: a managed care perspective. Diabetes Care. 2001;24:51-55.

33. Shetty SS, Secnik K, Oglesby AK. Relationship of glycemic control to total diabetes-related costs for managed care health plan members with type 2 diabetes. J Manag Care Pharm. 2005;11: 559-564.

34. Hertz RP, Unger AN, Lustik MB. Adherence with pharmacotherapy for Type 2 diabetes: a retrospective cohort study of adults with employersponsored health insurance. Clin Ther. 2005;27:1064-1073.

35. Vanderpoel DR, Hussein MA, Watson-Heidari T, Perry A. Adherence to a fixed-dose combination of rosiglitazone maleate/metformin hydrochloride in subjects with type 2 diabetes mellitus: a retrospective database analysis. Clin Ther. 2004;26:2066-2075.
ClinicoEconomics and Outcomes Research

\section{Publish your work in this journal}

ClinicoEconomics \& Outcomes Research is an international, peerreviewed open-access journal focusing on Health Technology Assessment, Pharmacoeconomics and Outcomes Research in the areas of diagnosis, medical devices, and clinical, surgical and pharmacological intervention. The economic impact of health policy and health systems

\section{Dovepress}

organization also constitute important areas of coverage. The manuscript management system is completely online and includes a very quick and fair peer-review system, which is all easy to use. Visit http://www.dovepress.com/testimonials.php to read real quotes from published authors. 